http://jmscr.igmpublication.org/home/ ISSN (e)-2347-176x ISSN (p) 2455-0450 crossref DOI: https://dx.doi.org/10.18535/jmscr/v8i3.65

\title{
Role of Computed Tomography in the Evaluation of Renal Masses
}

\author{
Authors \\ Dr Sapna Patel ${ }^{1}$, Dr Darshan Thummar ${ }^{2}$ \\ ${ }^{1}$ Assistant Professor, Dept. of Radiology, GCRI \\ ${ }^{2}$ Resident Doctor, Dept. of Radiology, GCRI
}

\begin{abstract}
Background and Objectives: The Introduction of Helical CT is one of many recent advances which create improvement in the detection and characterization of renal masses and compare the enhancement of renal mass and cortex and to evaluate the enhancement of renal veins and inferior vena cava during corticomedullary and nephrographic phase.

Methods: Study included 33 cases of renal masses was done for a period of 1 year from Nov 2018 to November 2019 in the department. Patients were evaluated thoroughly.

Results and Conclusions: For the final analysis thirty two patients were included (19 males and 13 females). Thirty three lesions were detected in thirty two patients. Of these, thirty lesions were neoplastic lesions of which majority of the neoplastic lesion comprised of Renal cell carcinoma (22 cases), Transitional cell carcinoma (3 cases), Angiomyolipoma (1 case), Renal oncocytoma (1 case), Renal metastasis (1 case), Renal abscess (1 case) and three lesions were cystic lesions.

1. Renal neoplasm showed greater enhancement in the nephrographic phase compared with that in corticomedullary phase ( $p=.001)$.

2. Renal cortex also showed greater enhancement in the nephrographic phase compared with that in corticomedullary phase ( $p=.001)$.

3. Renal vein are best visualized in corticomedullary phase and inferior vena cava is better visualized in nephrographic phase.
\end{abstract}

\section{Introduction}

Helical CT created many advances in the detection and characterization of renal masse. Helical CT is considered as the state of the art technology in the evaluation of abdominal pathology. It is modality of choice for suspected renal mass, its staging and detection of distinct metastases. Reason behind that are low cost, high accuracy and ready accessibility.

The commonest space occupying renal lesion is a simple cyst with an incidence of $25 \%-50 \%$ after the age of 50 years. Benign renal masses outnumber the malignant ones. Renal cell carcinoma is the most common tumor of the kidney comprising $3 \%$ of all malignancies found in adults.

The overall diagnostic accuracy of properly performed CT for separating cyst from neoplasmis extremely high.

Helical CT has many potential advantages over conventional axial CT. At the most commonly used pitch (ratio of table speed to image collimation) of $1: 1$, most kidneys can be scanned using narrow $(5 \mathrm{~mm})$ image collimation in less than 30 seconds. Such 
positioning improves the accuracy of range of interest measurements and the imager's ability to characterize a lesion by minimizing partial volume effects. The rapid scanning time of helical CT also permits renal imaging during any of the three phases of renal parenchymal contrast material enhancement: the cortical phase, nephrographic phase, or excretory phase.

\section{Aims and Objectives of the Study}

- To study the diagnostic accuracy of Helical $\mathrm{CT}$ in detection and characterization of renal masses.

- To compare the enhancement of renal neoplasm and renal cortex during corticomedullary and nephrographic phase.

- To evaluate the enhancement of renal veins and inferior venacava during corticomedullary and nephrographic phase.

\section{Methodology}

All patients referred to the department of Radio diagnosis with clinically suspected Renal mass lesions in a period of 1years from Nov 2018toNovember 2019will be subjected for the study.

The study includes

- All patients clinically suspected to have Renal mass lesions.

- All patients with incidentally diagnosed renal masses by ultrasound.

- Cases of all age groups irrespective of sex.

The study will exclude

Patient having history of trauma.

The pathological lesions were evaluated with respect to pre and post contrast attenuation values, the size, location of the mass, presence of calcification, presence of fat, and extension into the adjoining structures.

All CT diagnosis were obtained by a consensus of two senior radiologists.

\section{Results and Discussion}

In the present study, there were twenty males and thirteen females.

For the final analysis thirty two patients were included (19males and 13 females).

Thirty three lesions were detected in thirty two patients. Of these, thirty lesions were neoplastic lesions and three lesions were cystic lesions.

Table 1: Enhancement Data for Renal Neoplasms $(\mathrm{N}=20)$

\begin{tabular}{|l|c|}
\hline Variable & HU \\
\hline Unenhanced attenuation & $23 \pm 7$ \\
\hline CMP attenuation & $49 \pm 22$ \\
\hline NP attenuation & $68 \pm 26$ \\
\hline CMP enhancement & $23 \pm 14$ \\
\hline NP enhancement & $47 \pm 19$ \\
\hline
\end{tabular}

CMP-Corticomedullary phase, NP- Nephrographic phase, HU-Hounsfield units

One tumor, which showed greater degree of enhancement during corticomedullary phase, showed less enhancement during nephrographic phase.

Table -2: Enhancement Data For Renal Cysts

\begin{tabular}{|l|c|}
\hline Variable & Present study \\
\hline Unenhanced mean attenuation (HU) & $12 \pm 2$ \\
\hline Unenhanced attenuation Range (HU) & -5 to 28 \\
\hline CMP enhancement (HU) & $1 \pm 2$ \\
\hline NP enhancement (HU) & $2- \pm 3$ \\
\hline
\end{tabular}

The visibility of renal veins and inferior vena cava was assessed in corticomedullary and nephrographic phases. Renal veins were better visualized in corticomeduallary phase and inferior vena cava was better visualized in nephrographic phase.

Table -3: Summary of Enhancement Data

\begin{tabular}{|c|c|c|c|c|c|}
\hline $\begin{array}{l}\text { Region } \\
\text { Studied }\end{array}$ & $\begin{array}{c}\text { Unenhanced } \\
\text { attenuation (HU) }\end{array}$ & $\begin{array}{c}\text { CMP } \\
\text { Attenuation (HU) }\end{array}$ & $\begin{array}{c}\text { NP } \\
\text { Attenuation (HU) }\end{array}$ & $\begin{array}{c}\text { CMP } \\
\text { enhancement }(\mathbf{H U})\end{array}$ & $\begin{array}{c}\text { NP } \\
\text { enhancement }(\mathbf{H U})\end{array}$ \\
\hline Neoplasms & $232 \pm 7$ & $49 \pm 22$ & $68 \pm 26$ & $26 \pm 14$ & $45 \pm 19$ \\
\hline Cortex & $32 \pm 3$ & $137 \pm 30$ & $163 \pm 36$ & $105 \pm 29$ & $131 \pm 40$ \\
\hline Cysts & $12 \pm 2$ & $13 \pm 1$ & $14 \pm 2$ & $1 \pm 2$ & $2 \pm 3$ \\
\hline
\end{tabular}

The statistical significance of both renal neoplasms and normal renal cortex enhancement 


\section{JMSCR Vol||08||Issue||03||Page 370-374||March}

in the nephrographic and corticomedullary phases were calculated using student $\mathrm{t}$ test. Both renal neoplasms and renal cortex showed significantly greater enhancement in the nephrographic phase compared with that in the corticomeduallry phase ( $\mathrm{p}=.001$ and $\mathrm{p}=.001$ respectively).
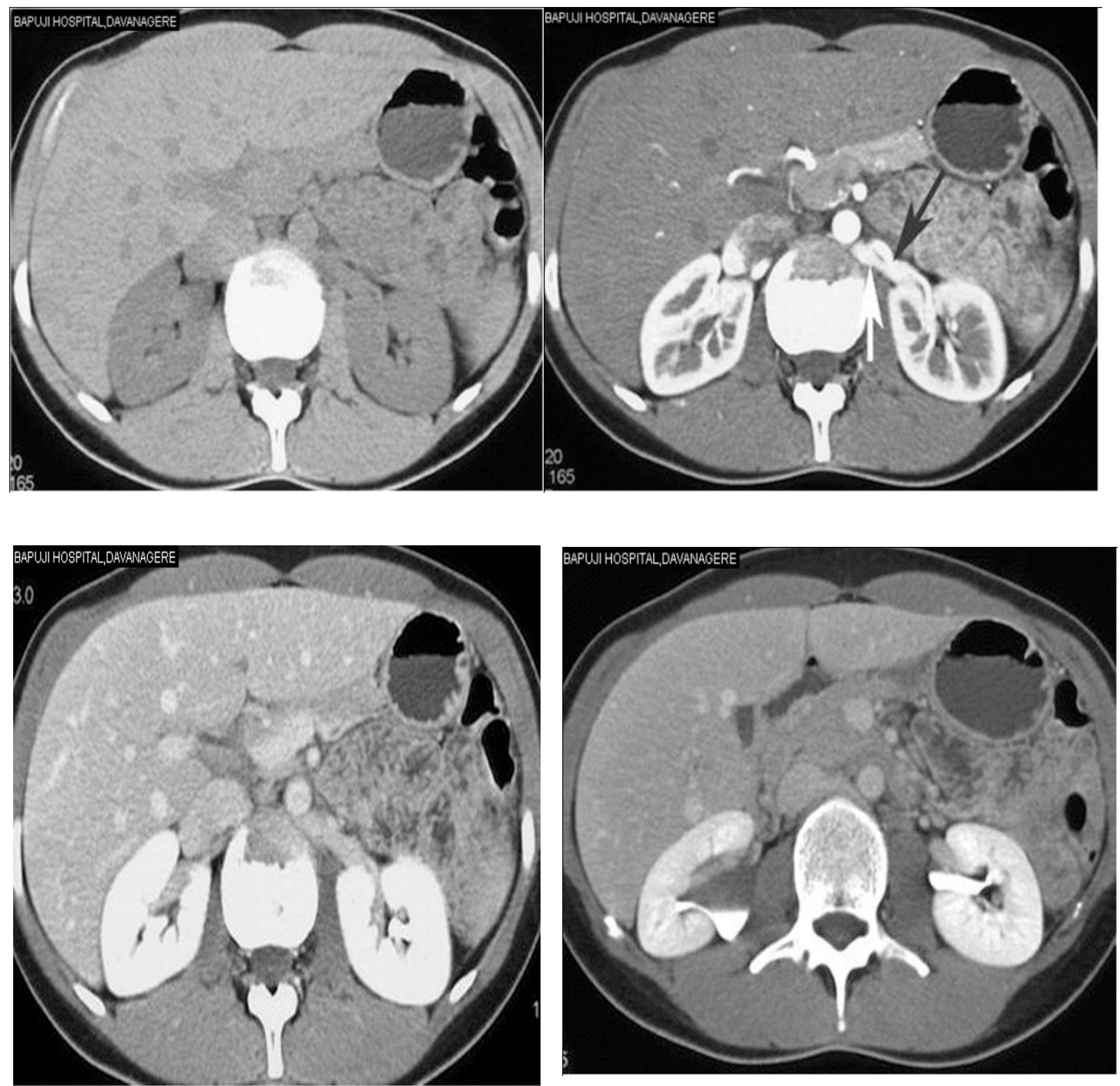

Images.1: Phases of renal enhancement at multidetector CT. (a) Unenhanced axial CT at level of renal hilum. (b) Late arterial phase axial CT at level of renal hilum. There is good opacification of the left renal artery (black arrow) and vein (white arrow). (c) Nephrographic phase axial CT at level of renal hilum. (d) Excretory phase axial CT at level of renal hilum.
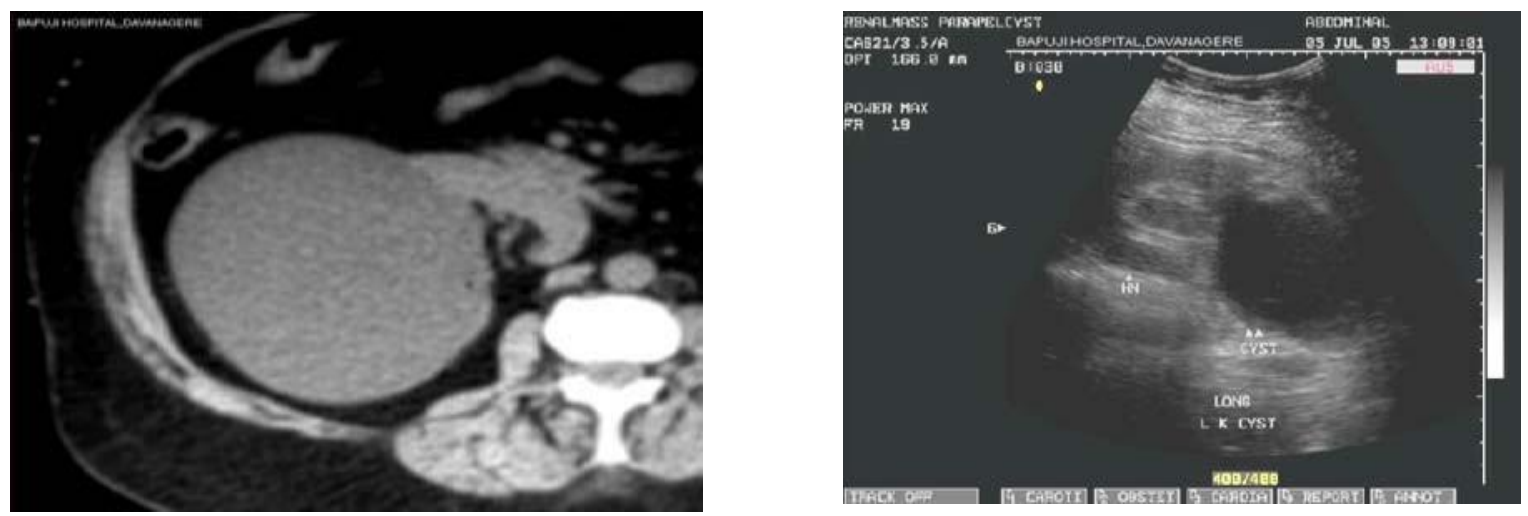

\section{Images $2 \mathrm{a}$ and $2 \mathrm{~b}$}

A Bosniak type II cyst with uniform high attenuation, no enhancement is seen.

B Well defined focal anechoic lesion in lower pole of left kidney-USG 


\section{JMSCR VoI||08||Issue||03||Page 370-374||March}

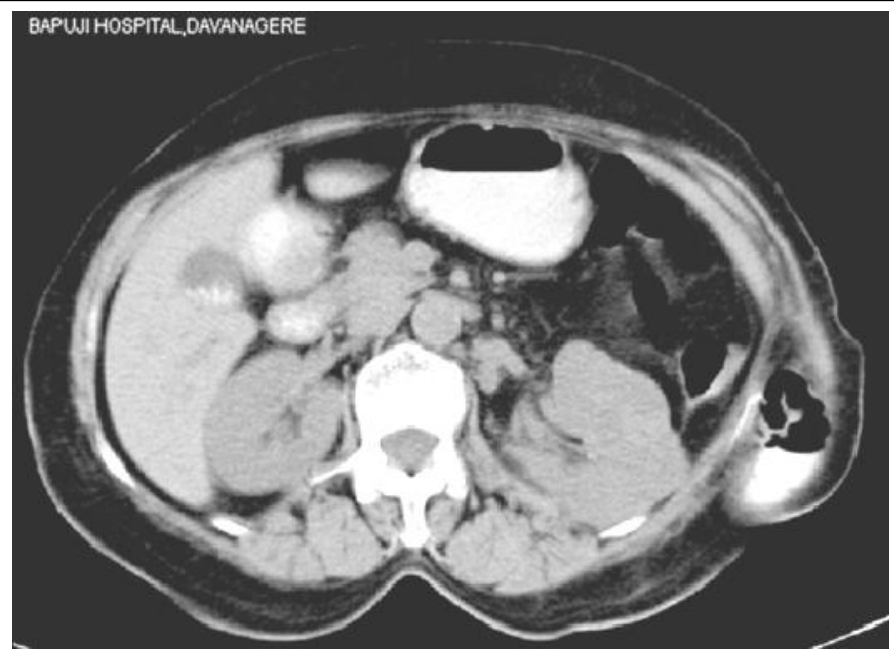

$\mathbf{a}$

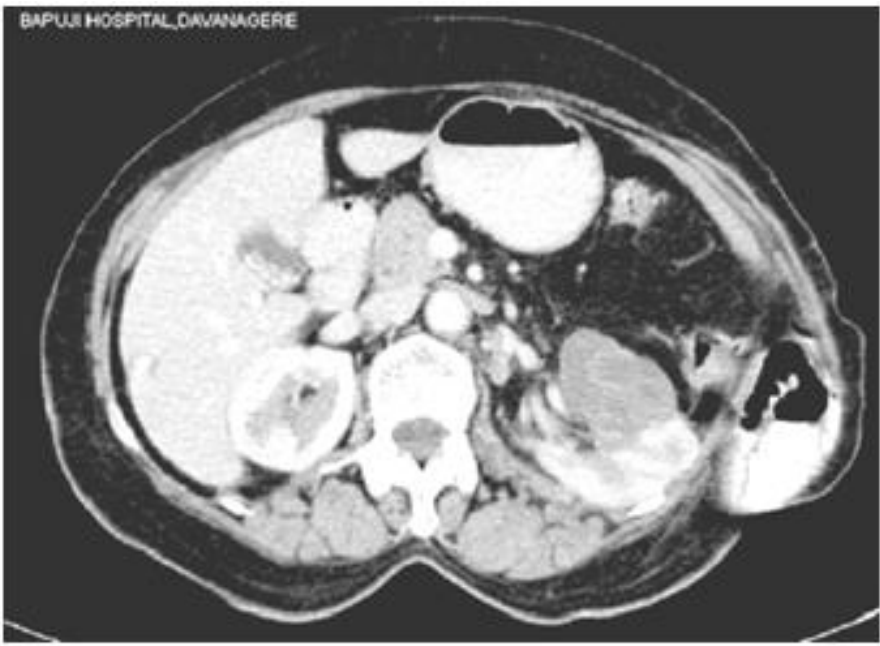

b

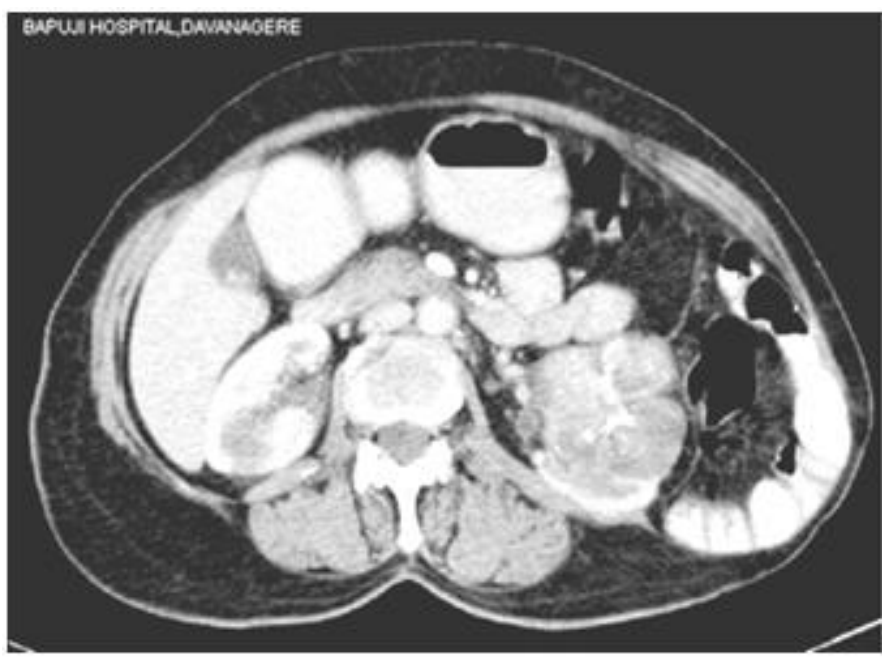

c

Images 3: Renal cell carcinoma - CT

a NECT showing soft tissue exophytic mass in left kidney

b Lesion shows enhancement on contrast administration

c Another case of RCC showing areas of calcification.

\section{Discussion}

The widespread use of USG and CT for survey examinations of abdomen has resulted in an increased rate of detection of both neoplastic and non neoplastic renal masses.

Previous studies ${ }^{1,2,3}$ have shown that nephrographic and excretory phase images are superior to corticomedullary phase in the detection of renal masses. Cohan et $\mathrm{al}^{4}$ demonstrated that small medullary lesions may be missed on corticomedullary phase and that falsepositive medullary pseudolesions may be detected due to disparate enhancement of medulla compared with that of the adjacent cortex.

Renal cortical enhancement in the nephrographic phase is more than that in the corticomedullary phase in all patients. These results correlated with the study conducted by Birnbaum et al $^{1}$., But our results are different from the study conducted by Cohan e $\mathrm{al}^{3}$., and Szolar etal ${ }^{2}$.,

Cohan et $\mathrm{al}^{3}$ studied cortical enhancement in corticomedullary and nephrographic phases. Mean attenuation of renal cortex in their study was 147 $\pm 41 \mathrm{HU}$ on corticomedullary phase images and $117 \pm 41 \mathrm{HU}$ on nephrographic phases images. They found that mean attenuation was $30 \mathrm{HU}$ greater in corticomedullary phase than in nephrographic phase images. In Szolar et al's ${ }^{2}$ study, mean cortical attenuation was $185 \pm 35 \mathrm{HU}$ in corticomedullary phase and $168 \pm 33 \mathrm{HU}$ in nephrographic phase. In their study, although mean cortical enhancement was slightly greater in corticomedullary phase images than that in nephrographic phase images, this was not statistically significant.

Analysis of summary enhancement data revealed that both renal neoplasms and normal renal cortex demonstrated significantly greater enhancement in the nephrographic phase compared with that in the corticomedullary phase $(\mathrm{p}=.001$ and .01 respectively). No statistically significant differences $(p>0.5)$ in enhancement were noted for the radiologically benign cysts when the two phases are compared. These results correlated with study conducted by Birnbaum et $\mathrm{al}^{1}$. 


\section{JMSCR VoI||08||Issue||03||Page 370-374||March}

\section{Conclusion}

1. Renal neoplasm showed greater enhancement in the nephrographic phase compared with that in corticomedullary phase $(\mathrm{p}=.001)$.

2. Renal cortex also showed greater enhancement in the nephrographic phase compared with that in corticomedullary phase $(\mathrm{p}=.001)$.

3. Renal vein are best visualized in corticomedullary phase and inferior vena cava is better visualized in nephrographic phase.

The enhancement values of Renal masses on contrast enhanced CT in nephrographic phase, corticomedullary phase determines the vascularity of the mass and hence determines the nature of the lesion.

Therefore, this study proves that Multiphasic Helical CT is a first line of investigation for determining the indeterminate lesion in comparison to other modalities.

\section{Bibliography}

1. Birnbaum BA, Jacobs JE, Ramchandani P. Multiphase renal CT ;Comparison of renal mass enhancement during the corticomedullary and nephrographic phase. Radiology.1996;200:753-758

2. Szolar DH, Kammerhuber F. Altzeibler S et al. Multiphasic helical CT of the kidney: Increased conspicuity for detection and characterization of small (<3cms) renalmasses. Radiology.1997;202:211-217

3. Cohan RH, Sherman LS, Korobkin M, et al: Renal masses: Assessment of corticomedullary-phase and nephrographicphase CT scans. Radiology 196:445-451, 1995.

4. Jeong Kon Kim, Soo-Youn Park, JeongHee Shon, and Kyoung-Sik Cho Angiomyolipoma with Minimal Fat: Differentiation from Renal Cell Carcinoma at Multidetector row CT of the kidneys Atadan Tunaci, Ensar Yekeler European Journal of Radiology - October 2004 (Vol.
52, Issue 1, Pages 56-66

5. Amendola MA, Bre RL, Pollack HM, Francis IR, Smal Renal cell carcinoma: Resolving a diagnosing dilemma, Radiology 1988;166:637-641. 